\title{
FORMULATION AND EVALUATION OF METRONIDAZOLE MICROSPHERES-LOADED BIOADHESIVE VAGINAL GEL
}

\author{
BANASMITA KALITA*, KRITIKA SAIKIA, BHUPEN KALITA
}

Department of Pharmaceutics, Girijananda Chowdhury Institute of Pharmaceutical Science, Azara, Guwahati, India. Email: banasmitakalita25@gmail.com

Received: 11 November 2016, Revised and Accepted: 24 December 2016

\section{ABSTRACT}

Objectives: The objective of the present work is to develop and characterize metronidazole microsphere-loaded bioadhesive vaginal gel to ensure longer residence time at the infection site, providing a favorable release profile for the drug.

Methods: Microsphere was prepared by solvent evaporation method in various ratios of metronidazole to poly- $\varepsilon$-caprolactone (PCL). Physicochemical evaluation of microspheres includes determination of solubility in simulated vaginal fluid, partition coefficient (n-octanol/citrate phosphate buffer pH 4.5), particle size distribution, entrapment efficiency, X-ray diffraction, and surface morphology by scanning electron microscopy (SEM). Drug excipient compatibility was established by Fourier transform infrared and differential scanning calorimetry studies. Bioadhesive gel was prepared using Carbopol 934P and HPMC K4M in various concentrations, and methyl paraben was used as a preservative. The pH was adjusted with triethanolamine which resulted in a translucent gel. The optimized metronidazole microsphere formulation was dispersed into the gel base. Microspheres in gel formulations were evaluated for $\mathrm{pH}$, viscosity, spreadability, drug content, and gelling strength. Ex vivo mucoadhesive strength of the gel was determined on goat vaginal mucosa. In vitro drug release study was performed using cellophane membrane.

Results: The optimized batch of microsphere F4 (drug-polymer ratio 1:4) showed entrapment efficiency of $72.62 \pm 3.66 \%$, solubility of 1.5 mg/ml, and partition coefficient of 0.12 . Particle size of all the formulations was observed below $100 \mu \mathrm{m}$. Regular and spherical particles were observed in the SEM photomicrographs. The optimized gel formulation G5 (Carbopol and HPMC at 1: 0.25 ratio) showed viscosity of 7538 cps at 100 RPM, gel strength recorded as 35 secobds for a $1000.00 \mathrm{mg}$ load, and spreadability of 4.6 g.cm/seconds. G5 showed $82.4 \%$ drug release at 10.0 hrs and mucoadhesive strength of $6.5 \pm 1.2 \mathrm{~g}$.

Conclusion: The study results suggest that metronidazole-loaded PCL microsphere in mucoadhesive gel would provide a mean for sustained treatment of vaginal infections.

Keywords: Microsphere, Metronidazole, Bioadhesive vaginal gel.

(c) 2017 The Authors. Published by Innovare Academic Sciences Pvt Ltd. This is an open access article under the CC BY license (http://creativecommons. org/licenses/by/4. 0/) DOI: http://dx.doi.org/10.22159/ajpcr.2017.v10i3.16417

\section{INTRODUCTION}

Vaginal drug delivery system is the system where the drug formulations are applied directly in the vaginal cavity for producing systemic and local action, and is considered important because the vaginal membrane has a dense network of blood vessels for effective drug absorption, large surface area, local effect, self-insertion, rich blood supply, and avoidance of the first-pass effect. The vaginal route is particularly used to treat vaginal infections, sexually transmitted diseases, or for contraception. Semisolid and solid dosage forms are preferred for this route and such dosage when tailored with bioadhesion properties prolongs the residence time in the vaginal cavity [1]

Metronidazole is a member of the imidazole class of antibacterial agents and is classified therapeutically as an antiprotozoal [2] and antibacterial agent [3]. Chemically, metronidazole is 2-methyl-5nitroimidazole-1-ethanol (Fig. 1). It acts against protozoa such as Trichomonas vaginalis, amebiasis, and giardiasis. It selectively acts against anaerobic bacteria. It disrupts DNA's helical structure, thereby inhibiting bacterial nucleic acid synthesis. This eventually results in bacterial cell death [4]. Metronidazole is reported to have low bioavailability in vaginal route of administration (20-25\%). It has low lipid solubility that probably contributes to its poor vaginal absorption. There are reports available on metronidazole-loaded microsphere system with better permeability to provide constant and prolonged therapeutic effect [5]. Microspheres are the small spherical particles that have the diameters in the micrometer range (typically $1 \mu \mathrm{m}$ to $1000 \mu \mathrm{m}$ ) [6]. Such prolonged acting system reduces the dosing frequency and improves the patient compliance [7]. Better drug utilization in the form of microspheres improves bioavailability and reduces the incidence or intensity of adverse effects. In addition, microsphere morphology allows a controllable variability in degradation and drug release [8]

Advancement of vaginal drug delivery was aided by mucoadhesive gel formulations. Kumar et al. (2014) reported in vitro-in vivo evaluation of microspheres-loaded topical gel delivery system of ketoconazole in male rats against Candida glabrata. They revealed that microspheresloaded gel of ketoconazole offers a convenient dosage form for achieving better release profiles and improved patient compliance. Dhaliwal et al. (2013) worked on preparation and characterization of bioadhesive vaginal gel of propranolol hydrochloride. They revealed that the films containing higher concentration of polymers released the drug slowly as compared to the formulations with lower concentration. The formulations maintained the sustained drug release for more than 54 hrs. Patel et al. (2013) worked on the formulation and evaluation of bioadhesive gel-incorporated amoxicillin trihydrateloaded microspheres for periodontal therapy. They found that the gel formulation, which consisted of drug-loaded gelatin microspheres, showed sustained release of amoxicillin trihydrate for more than $6 \mathrm{hrs}$. Yellanki et al. (2010) worked on the development of metronidazole intravaginal gel for the treatment of bacterial vaginosis. They concluded 


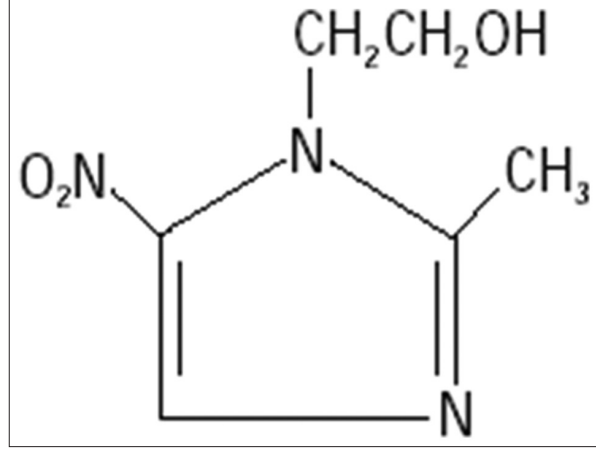

Fig. 1: Molecular formula of metronidazole

that the bioadhesive intravaginal gel formulations are more effective as well as have better patient compliance than the existing conventional vaginal drug delivery systems. Tiwari (2010) worked on biodegradable microspheres for controlled delivery of metronidazole in the treatment of periodontal diseases. The study results suggested that the novel blend microparticles prepared from poly (L-lactic-co-glycolic acid) and poly- $\varepsilon$-caprolactone (PCL) are effective in controlled delivery of metronidazole to periodontal therapy. In the light of the literature reviewed, the present work proposed to develop metronidazole-loaded polycaprolactone microsphere and incorporation of the metronidazole microspheres in mucoadhesive gel for the treatment of vaginal infections. Carbopol 934 is widely used as mucoadhesive polymer in gel formulations and forms adhesive bond between a biological and a synthetic surface. Polycaprolactone is biodegradable polyester with low melting point of around $60^{\circ} \mathrm{C}$ and a glass transition temperature of about $60^{\circ} \mathrm{C}$. Poly- $\varepsilon$-caprolactone (PCL) has been receiving increasing attention as matrix material for controlled release drug formulations. PCL and its derivatives, with a high permeability to many therapeutic drugs and lack of toxicity and non-irritability, is well suited for controlled drug delivery. However, the utilization of PCL is not explored largely and limited reports were found in the area of controlled vaginal drug delivery.

\section{MATERIALS AND METHODS}

\section{Materials}

Metronidazole, PCL, and carbopol 934P were purchased from Balaji Drugs, Mumbai, India. HPMC K4M, triethanolamine, and polyvinyl alcohol (PVA) were purchased from Merck Specialist Pvt. Ltd, Mumbai. All the other chemicals and reagents used in this study were of analytical grade.

\section{Methods}

\section{Preparation of microspheres}

Microspheres were prepared at room temperature by solvent evaporation technique using the quantity of drug and other excipients as given in the Table 1. PCL solution was prepared by dissolving PCL in dichloromethane (DCM). Under mechanical stirring with a three-blade propeller (REMI- RQ 122), the organic phase $(10 \mathrm{~mL})$ was poured into $500 \mathrm{~mL}$ of water containing PVA (1\%). Then, stirring was maintained for $1 \mathrm{hr}$ at different rpm, leading to a total evaporation of the solvent (DCM). The microspheres were then recovered by filtration, washed three times with double-distilled water, and dried at room temperature for the next $24 \mathrm{hrs}[9,10]$.

\section{Formulation of mucoadhesive carbopol gel}

Carbopol 934P was soaked overnight in minimum quantity of water and allowed to swell up. After $24 \mathrm{hrs}$, HPMCK4M was dispersed in various concentrations. Metronidazole microspheres were dispersed into the gel base. Methyl paraben was mixed as a preservative. The $\mathrm{pH}$ was adjusted with triethanolamine which resulted in a translucent gel. The quantity of carbopol 934P, HPMCK4M methyl paraben and distilled water were used as given in the Table 2 [11].
Drug excipient compatibility study by Fourier transform infrared (FT-IR) and differential scanning calorimetry (DSC) FT-IR study

The excipients were mixed individually with the pure drug in a ratio of 1:1 and the spectra were recorded using FT-IR Bruker, Alpha. The scanning range was $400-4000 \mathrm{~cm}^{-1}$ and the resolution was $2 \mathrm{~cm}^{-1}$ [12]

\section{DSC study}

The excipients were mixed individually with the pure drug in a ratio of 1:1, and the DSC study was performed. DSC of the bulk drug metronidazole was performed using DSC instrument (Perkin Almer, U.S.A.) for measurement of the heat loss or gain resulting from the physical or chemical changes within a sample as a function of temperature. About 6-7 $\mathrm{mg}$ of the individual component or drug excipient combinations were weighted in aluminum DSC pans, and hermetically sealed capsules were prepared with aluminum lids. An initial ramp was used to jump the temperature to $40^{\circ} \mathrm{C}$ and then a constant heating rate of $10^{\circ} \mathrm{C} /$ minutes was used up to $300^{\circ} \mathrm{C}$ under nitrogen atmosphere [13].

\section{Evaluation of microsphere}

Particle size studies

The particle size of microspheres was determined using an optical microscopy method. Approximately, 100 microspheres were counted using a calibrated microscope [14].

\section{Scanning electron microscopy (SEM)}

The shape and surface morphology of the microspheres was observed by SEM. The microsphere sample was thinly spread onto a metal stub and vacuum coated with a thin layer of gold in an argon atmosphere. The SEM photographs of the coated particles were obtained at $15 \mathrm{kV}$ using an SEM, ZEISS, Germany [15].

\section{Partition coefficient study}

A separating funnel was thoroughly cleaned and dried into which $20 \mathrm{ml}$ of n-octanol and $20 \mathrm{ml}$ of citrate phosphate buffer $\mathrm{pH} 4.5$ were taken. About $10 \mathrm{mg}$ of microsphere was added to it. Then, the funnel was shaken on a mechanical shaker for $24 \mathrm{hrs}$. The organic and aqueous fractions were separated. From the aqueous fraction, $0.5 \mathrm{ml}$ of sample was withdrawn and diluted to $10 \mathrm{ml}$ with distilled water. Then, the absorbance was measured at $309 \mathrm{~nm}$ using ultraviolet (UV) spectrophotometer (Shimadzu- Model No. UV 1800) [16].

\section{Saturation solubility study of microsphere}

The excess amount of drug was taken and added to $5 \mathrm{ml}$ solvent (water, phosphate buffer $\mathrm{pH}$ 6.8, and citrate phosphate buffer $\mathrm{pH} 4.5$ ) in a tightly capped glass vial. To mix properly, the sample was constantly agitated at $80 \mathrm{rpm}$ at room temperature for 24 hrs in REMI rotary shaker. At the end of $24 \mathrm{hrs}$, the samples were centrifuged in a REMI centrifuge at $1000 \mathrm{rpm}$. The supernatant liquid was separated and from that $0.5 \mathrm{ml}$ was transferred to $10 \mathrm{ml}$ volumetric flask. The volume was made up to the mark with distilled water. Absorbance was determined at $\lambda_{\max } 309 \mathrm{~nm}$ against citrate phosphate buffer as blank using UV spectrophotometer [17].

Table 1: Formulation of metronidazole microspheres

\begin{tabular}{lllll}
\hline $\begin{array}{l}\text { Formulation } \\
\text { code }\end{array}$ & $\begin{array}{l}\text { Drug-polymer } \\
\text { ratio }\end{array}$ & PVA (\%) & Time (hr) & RPM \\
\hline F1 & $1: 1$ & 1 & 1 & 1200 \\
F2 & $1: 0.5$ & 1 & 1 & 1200 \\
F3 & $0.5: 1$ & 1 & 1 & 1200 \\
F4 & $1: 0.75$ & 1 & 1 & 1200 \\
F5 & $0.75: 1$ & 1 & 1 & 1200 \\
F6 & $1: 0.25$ & 1 & 1 & 1200 \\
F7 & $0.25: 1$ & 1 & 1 & 1200 \\
\hline
\end{tabular}

PVA: Polyvinyl alcohol 
Table 2: Formulation of gel

\begin{tabular}{lllll}
\hline Formulations & Carbopol934p (\% w/v) & HPMC K4M (\% w/v) & Methyl paraben & Distilled water \\
\hline G1 & 1 & - & 0.02 & q.s \\
G2 & 1 & 1 & 0.02 & q.s \\
G3 & 1 & 0.75 & 0.02 & q.s \\
G4 & 1 & 0.5 & 0.02 & q.S \\
G5 & 1 & 0.25 & 0.02 & q.s \\
G6 & 1 & 0.125 & 0.02 & q.s \\
\hline
\end{tabular}

\section{Drug entrapment efficiency}

Microspheres equivalent to $5 \mathrm{mg}$ metronidazole were crushed using a glass mortar and pestle. Then, they were suspended in $25 \mathrm{ml}$ of citrate phosphate buffer $\mathrm{pH} 4.5$. After $24 \mathrm{hrs}$, the solution was filtered and $1 \mathrm{ml}$ of the filtrate was diluted 10 times and analyzed for the drug content by UV-visible spectrophotometer at $309 \mathrm{~nm}$ [18]. The drug entrapment efficiency was calculated using the following formula:

Entrapment efficiency $=($ actual drug content/theoretical drug content) $\times 100$.

\section{In vitro drug release study}

The in vitro release of metronidazole microspheres was done in citrate phosphate buffer $\mathrm{pH} 4.5$ for 7 hrs in USP-I Basket-type dissolution apparatus at a temperature of $37^{\circ} 0 \pm 0.5^{\circ} \mathrm{C}$. The volume of the dissolution medium was $900 \mathrm{ml}$ and agitated at $100 \mathrm{rpm}$ throughout the study. Microspheres equivalent to $10 \mathrm{mg}$ of drug were taken and they were transferred in the basket wrapping it with muslin cloth. The sample was taken in every half an hour for $7 \mathrm{hrs}$. To maintain the sink condition, the samples withdrawn were replaced with an equal volume of dissolution medium. After suitable dilution, samples were analyzed by UV-visible spectrophotometer at $309 \mathrm{~nm}$ [19].

\section{Evaluation of microspheres-loaded gel Determination of $\mathrm{pH}$}

Determination of $\mathrm{pH}$ was done by Indosati Digital $\mathrm{pH}$ meter (Systronics, 335). $\mathrm{pH}$ meter was calibrated before use using standard buffer solution [11]

\section{Viscosity}

The viscosities of the formulated gels were determined by Brookfield viscometer using spindle no. 64 (DV-E Viscometer) [20]

\section{Gel strength determination}

A composition of $50 \mathrm{~g}$ of microspheres-loaded gel was taken in a $10 \mathrm{ml}$ beaker. The weight of $1000 \mathrm{mg}$ for measuring gel strength was allowed to penetrate into the gel. The gel strength, which means the viscosity of the gel, was determined by time (seconds), the weight took to sink $5 \mathrm{~cm}$ down through the prepared gel [21].

\section{Spreadability}

A sample of $0.5 \mathrm{~g}$ of each formulation was pressed between two slides (divided into squares of $5 \mathrm{~mm}$ sides) and left for about 5 minutes where no more spreading was expected. Diameters of spreaded circles were measured in $\mathrm{cm}$ and were taken as comparative values for spreadability. The results obtained are average of three determinations [22]

\section{Drug content}

About $0.5 \mathrm{~g}$ of gel was dissolved in $25 \mathrm{~mL}$ citrate phosphate buffer at $\mathrm{pH}$ 4.5. It was then filtered after constant stirring and analyzed by UV spectrophotometer after suitable dilution at $309 \mathrm{~nm}$ [23].

\section{Mucoadhesive strength}

Mucoadhesive strength was determined using texture analyzer (TA. XT EXPRESS). The mucoadhesive strength of the formulations was evaluated by measuring the force required to detach the formulation from a goat vaginal mucosa. Goat vaginal mucosa was obtained from a local slaughter shop; it was cleaned, subcutaneous fat and blood vessels were removed with a scalpel, washed thoroughly with doubledistilled water, and blotted dry by a tissue paper. Gel was heated to $37^{\circ} \mathrm{C}$ so that it undergoes complete gelation and remains attached to the probe of the texture analyzer. Goat vaginal mucosa (about $2 \times 2 \mathrm{~cm}^{2}$ ) was dipped in citrate phosphate buffer at $\mathrm{pH}$ 4.5. It was then placed in the plate attached to the texture analyzer; target force of $500.0 \mathrm{mg} /$ sec was applied. After keeping in contact for $10 \mathrm{~s}$, the probe was then moved vertically upward at a constant speed of $5 \mathrm{~mm} \mathrm{~s}^{-1}$. Maximum detachment force (F) was obtained from the force-distance graph [24].

\section{In vitro drug release study}

In vitro release studies of metronidazole microspheres from the carbopol gel were carried out at $37^{\circ} \mathrm{C}$ using citrate phosphate buffer $(\mathrm{pH} \mathrm{4.5)}$ as the release medium. A glass tube of $10 \mathrm{~mm}$ diameter and $100 \mathrm{~mm}$ height was taken. One end of the tube was closed using cellophane membrane with the help of an adhesive tape, while the other end was kept open and used as drug reservoir compartment. Gel (1 g) containing metronidazole microspheres was accurately weighed and transferred to the glass tube in a vertical position through the open end. The gel was gently pushed down to the surface of the membrane. Citrate phosphate buffer $(2 \mathrm{ml}, \mathrm{pH} 4.5)$ was added to the reservoir compartment to wet the gel. The glass tube was placed in a beaker containing $100 \mathrm{ml}$ of citrate phosphate buffer ( $\mathrm{pH} 4.5$ ), in such a way that the membrane just touches the release medium. The receiving compartment was magnetically stirred (100 rpm, REMI, India) at $37^{\circ} \mathrm{C}$. Samples $(1 \mathrm{ml})$ were withdrawn from the receiving compartment at regular intervals, and the amount of metronidazole released from the gel was determined using a spectrophotometer at $309 \mathrm{~nm}$. After each withdrawal of sample, equal quantity of citrate phosphate buffer was added to the receiving compartment to maintain the sink condition [25].

Antimicrobial efficacy study of metronidazole microspheresloaded bioadhesive carbopol vaginal gel

Antimicrobial efficacy studies were performed to ascertain the biological activity of the optimized vaginal gel batch G5 against Candida species (Candida albicans). The antifungal activity of the optimized formulation G5 was compared with the marketed formulation of MIZ cream. This was determined by agar diffusion test employing "cup and plate technique." Marketed formulation of MIZ as a standard and optimized formulation was poured into cups bored into sterile Sabouraud dextrose agar medium previously seeded with Candida test organism. The Sabouraud dextrose agar media were prepared by suspending $40 \mathrm{~g}$ of dextrose, $10 \mathrm{~g}$ of peptone, and $15 \mathrm{~g}$ of agar in $1000 \mathrm{ml}$ of distilled water. The wells were filled with $0.16 \mathrm{~g}$ of marketed as well as optimized formulation with the help of a sterile syringe. The plates were kept at room temperature for 45 minutes to allow diffusion of gel in the inoculated medium. Thereafter, all the plates were kept at $27^{\circ} \mathrm{C}$ and $37^{\circ} \mathrm{C}$ to check for fungal and bacterial growth, respectively, in the incubator for $24 \mathrm{hrs}$. The zone of inhibition was measured around each cup with Antibiotic zone scale (Himedia Laboratories Limited) and was compared with that of standard [26].

\section{RESULTS AND DISCUSSION}

Drug excipient compatibility study using FT-IR

FT-IR spectrum of drug and drug-polymer mixture is shown in Figs. 2 and 3, respectively. From the FT-IR spectra of drug and drug- 


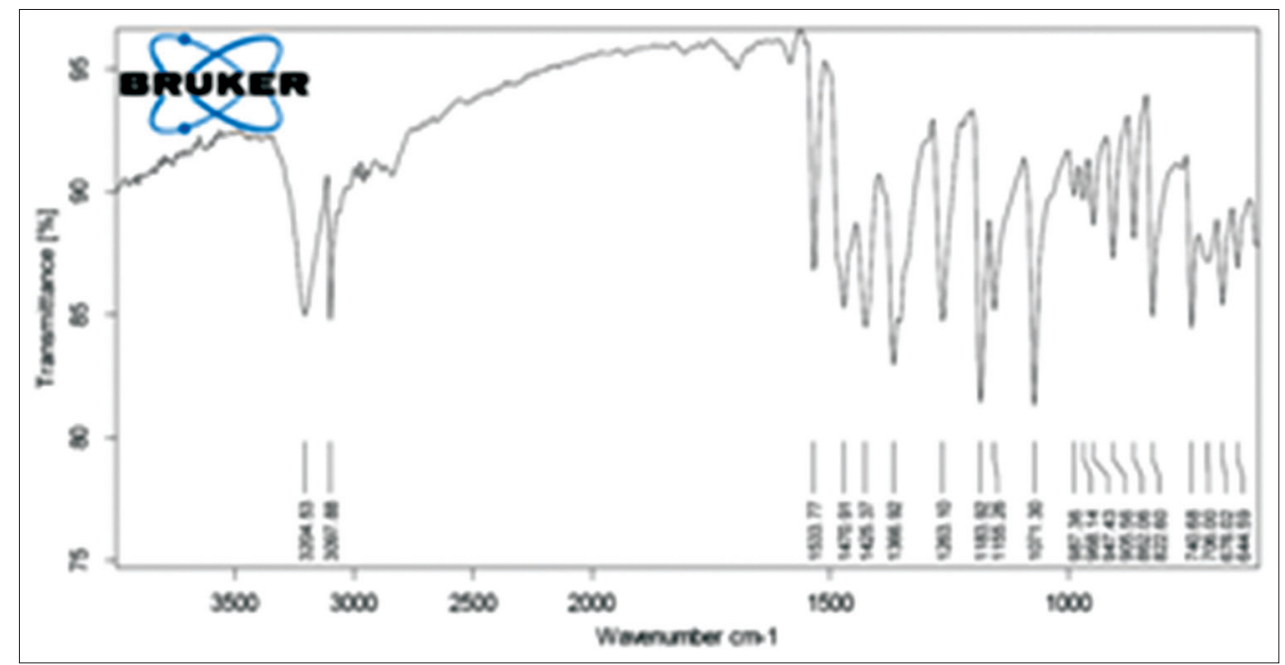

Fig. 2: Fourier transform infrared spectra of metronidazole

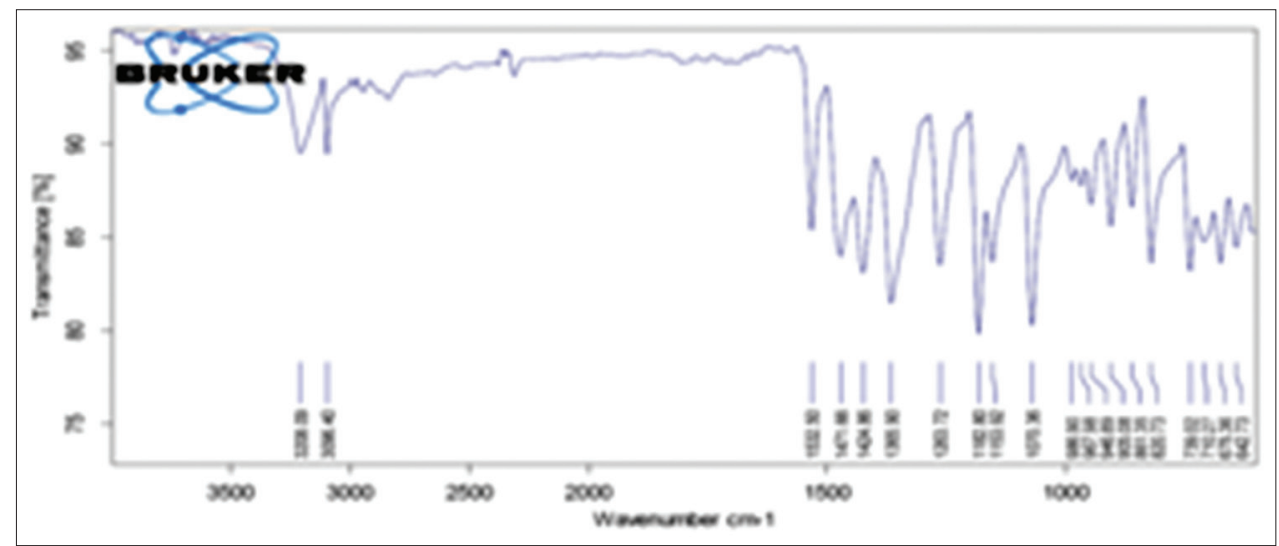

Fig. 3: Fourier transform infrared spectra of physical mixture of drug and polymer (poly- $\varepsilon$-caprolactone)

polymer mixture, it was found that drug and polymer are compatible with each other.

\section{Drug excipient compatibility study using DSC}

For the preparation of a drug formulation, it is necessary to evaluate the interactions between the drug and the polymers. The DSC thermogram of pure metronidazole shows a sharp endothermic peak at $165.27^{\circ} \mathrm{C}$ which corresponds to its melting point. The thermogram of metronidazole with polycaprolactone shows sharp endothermic peak at $164.90^{\circ} \mathrm{C}$, due to the presence of metronidazole. Thus, the thermal data shown in the Fig. 4, did not reveal any interaction between the drug and polymer.

Physico-chemical characteristics

Results show that the particle size of the prepared microspheres varied from 10.25 to 35.56 as shown in Table 3. The size of microspheres decreased with increase in polymer concentration.

The partition coefficients of the microspheres are listed in Table 3, and the microspheres showed better permeation than the drug metronidazole.

The average entrapment efficiency (\%) of metronidazole microsphere formulations is shown in Table 3 and was found to be $58.54 \pm 1.18$, $63.32 \pm 2.1, \quad 53.32 \pm 0.95, \quad 72.62 \pm 3.66, \quad 69.12 \pm 3.5, \quad 56.40 \pm 1.1$, and $50.24 \pm 0.98$ in the formulations F1, F2, F3, F4, F5, F6, and F7. The average entrapment efficiency of the formulations increased with increase in polymer concentration. The maximum entrapment efficiency $(72.62 \pm 3.66)$ was observed in formulation F5. The change in drug entrapment may be due to poor aqueous solubility and high binding capacity of drug on polymer surface.

SEM

The microspheres prepared by solvent evaporation method have good spherical shape with smooth surface in its morphology, and the particles were distributed uniformly without forming any clump and it is shown in the Fig. 5. Particle sizes observed in SEM photomicrographs are in the same line as determined by optical microscopic method.

\section{Release study of microspheres}

In vitro release profile of metronidazole-loaded microspheres in citrate phosphate buffer pH 4.5 is shown in Fig. 6. Here, sustained release of drug was observed from the formulation in citrate phosphate buffer $\mathrm{pH} 4.5$ for duration of $6 \mathrm{hrs}$. Here, we found that drug release is dependent on the concentration of the polymer that may be due to the hydration capability of polymer which on coming in contact with dissolution medium forms gelatinous mass that is retardant material for the drug to get diffused out. The cumulative percentage drug release from formulations F1, F2, F3, F4, F5,F6, and F7 is 68.9,73.6, $69.5,86.9,75.8,56.9$, and 65.3. Thus, F4 formulation has higher drug release in citrate phosphate buffer $\mathrm{pH} 4.5$ in comparison to the other formulations.

\section{Evaluation of mucoadhesive gel}

$\mathrm{pH}$ of the formulation was found in the range of 3.93-4.88, that is within the limit of vaginal semisolid specifications. The normal $\mathrm{pH}$ of 
Table 3: Mean particle size, partition coefficient, saturation solubility, and percentage drug entrapment efficiency of microsphere

\begin{tabular}{llll}
\hline Formulation & Mean particle size $(\boldsymbol{\mu m})$ & Partition co efficient & Saturation solubility (mg/ml) \\
\hline F1 & & \\
Pefficientage drug entrapment
\end{tabular}

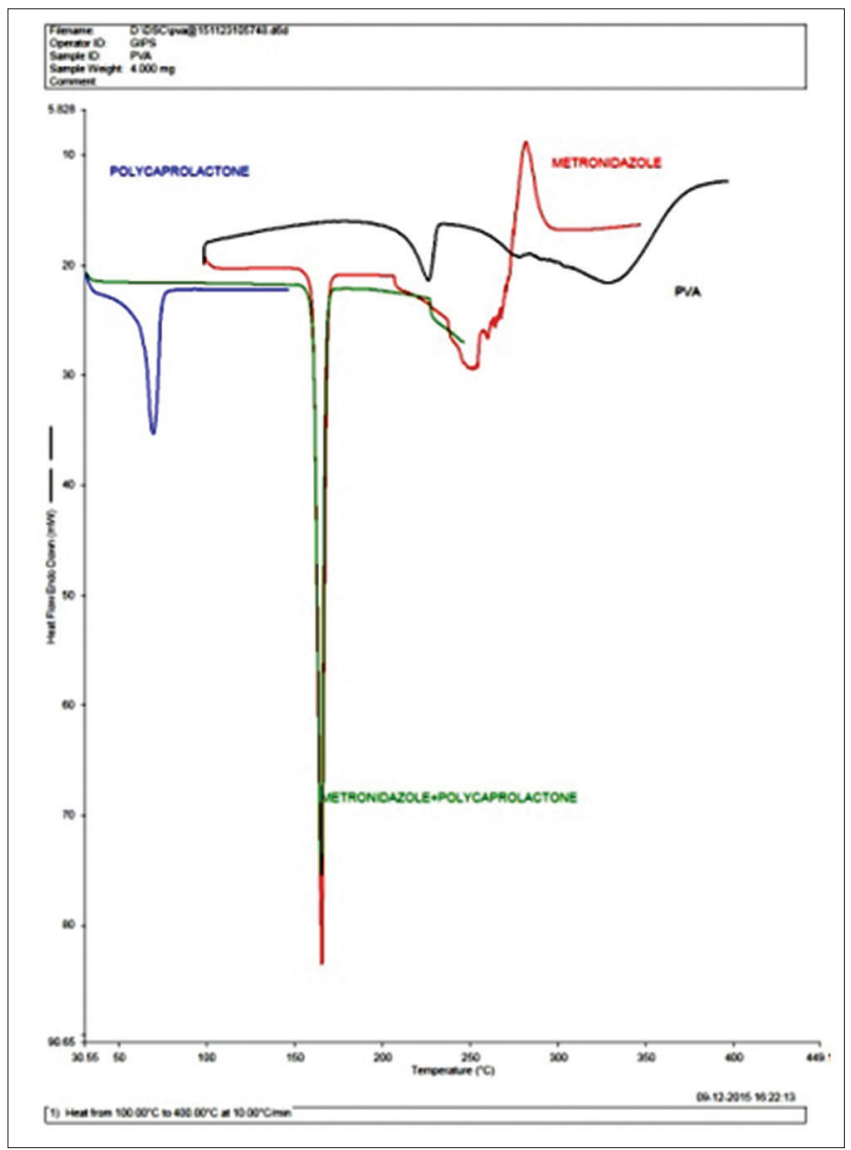

Fig. 4: Differential scanning calorimetry study of physical mixture of drug and polymer (poly- $\varepsilon$-caprolactone)

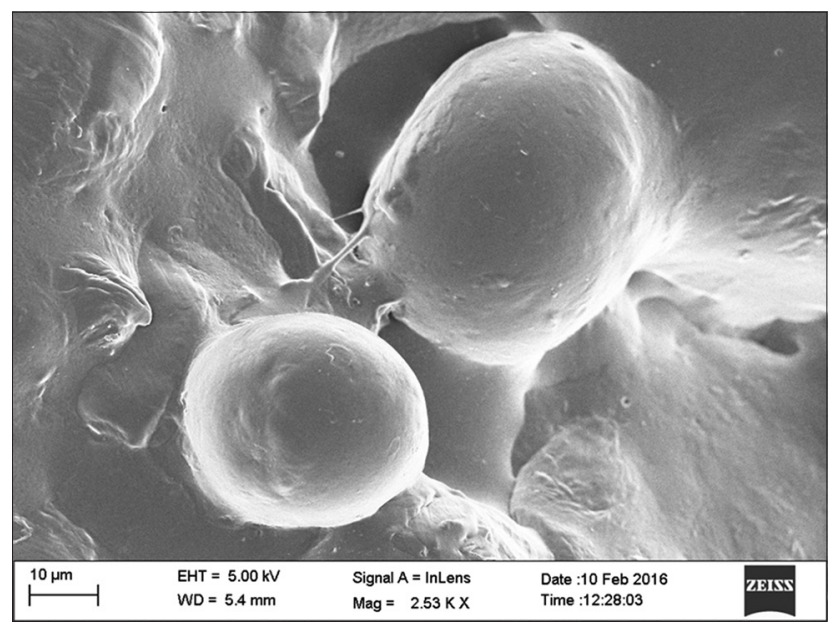

Fig. 5: Scanning electron microscopy of metronidazole microsphere

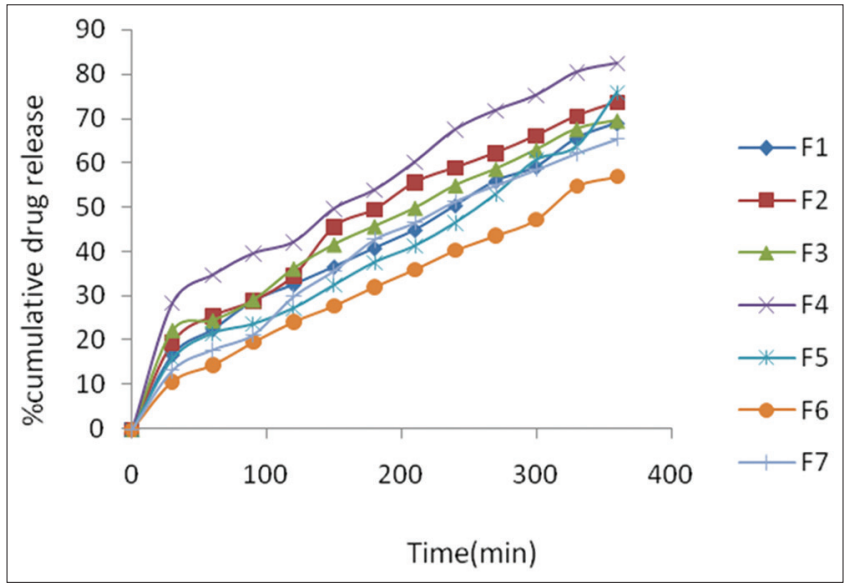

Fig. 6: Drug release study of metronidazole microsphere

the vagina is in between 4 and 5 . This indicates the nonirritancy of the formulation in the vaginal cavity. Viscosity increases with the increase in the concentration of the mucoadhesive polymer. Viscosity also decreases with the increase in the RPM. The value for viscosity of all the formulations is shown in Table 4. Spreadability of the formulated gels was found to be within the range of 3.5-5.5 g.cm/sec. As the viscosity of the formulation increases, the spreadability of the formulation decreases. The values of spreadability are shown in Table 5. Gel strength is calculated in time(s) and found within the range of $28-52 \mathrm{sec}$. The values of gel strength are shown in Table 5. Mucoadhesive strength was found within the range of 3.5-15.6 g. Drug content of all the formulation was found within the range of $52.30-70.02 \%$ as shown in Table 5 .

\section{In vitro diffusion study of gel}

In vitro diffusion study of bioadhesive gel incorporated metronidazoleloaded microspheres and compared with metronidazole microspheres. The cumulative release of metronidazole from microspheres and gel is shown in Fig. 7. Drug from the microspheres was released in a controlled manner. The release pattern was biphasic with an initial "burst" release of $28.4 \%$ of the loaded drug in the first 30 minutes. Thereafter, release was slow but steady, and by the end of the $7^{\text {th }} \mathrm{hr}$, a maximum of $86.9 \%$ of the loaded drug was released (F4).

Metronidazole from the carbopol gel formulation is also shown in Fig. 7. The release pattern was biphasic with an initial "burst" release that was enhanced by the loading dose of metronidazole. By the end of the first 30 minutes, $10.6 \%$ of the drug was released; subsequently, release was steady, and by the end of the $10^{\text {th }} \mathrm{hr}$, a maximum of $82.4 \%$ of the drug was released.

The antimicrobial activity of optimized batch was compared with the marketed formulation of MIZ cream using cup and plate technique. Table 6 and Fig. 8 show the result for antimicrobial efficacy studies that the zone of inhibition of optimized batch was found to be almost similar to that of marketed formulation. Mundhey et al. found $38 \mathrm{~mm}$ and $33 \mathrm{~mm}$ zone of inhibition for the optimized and marketed formulations of MTZ gel, respectively. 
Table 4: Viscosity of microspheres-loaded gel

\begin{tabular}{lllllll}
\hline RPM & \multicolumn{2}{l}{ Gel formulations } & & & \\
\cline { 2 - 6 } & G1 & G2 & G3 & G4 & G5 \\
\hline 1 & 490300 & 360600 & 383059 & 290630 & 250905 \\
5 & 104210 & 94200 & 199583 & 85039 & 168900 & 76012 \\
20 & 49000 & 36900 & 75308 & 58390 & 8905 \\
50 & 10300 & 9380 & 24595 & 12978 & 750 \\
100 & 9380 & 7589 & 10298 & 9730 & 12905 \\
\hline
\end{tabular}

Table 5: Spreadability, bioadhesive strength, and gel strength of microspheres-loaded gel

\begin{tabular}{|c|c|c|c|c|c|}
\hline Gel code & pH & Gel strength (sec) & Bioadhesive strength (gm) & Spread ability (g.cm/sec) & Drug content (\%) \\
\hline G1 & 4.09 & 45 & $5.7 \pm 1.2$ & 3.5 & $62.30 \pm 0.02$ \\
\hline G2 & 4.86 & 52 & $7.2 \pm 2.4$ & 4.4 & $64.68 \pm 0.12$ \\
\hline G3 & 3.93 & 42 & $3.5 \pm 2.3$ & 5.2 & $61.39 \pm 1.2$ \\
\hline G4 & 4.04 & 38 & $15.6 \pm 4.3$ & 5.5 & $58.90 \pm 0.043$ \\
\hline G5 & 4.02 & 35 & $6.5 \pm 1.2$ & 4.6 & $70.34 \pm 1.2$ \\
\hline G6 & 4.88 & 32 & $5.9 \pm 3.2$ & 4.2 & $69.38 \pm 1.3$ \\
\hline
\end{tabular}

Table 6: Antimicrobial efficacy study

\begin{tabular}{lll}
\hline \multirow{2}{*}{$\begin{array}{l}\text { Fungal } \\
\text { species }\end{array}$} & \multicolumn{2}{l}{ Zone of inhibition (mm) } \\
\cline { 2 - 3 } & $\begin{array}{l}\text { Optimized } \\
\text { formulation }\end{array}$ & $\begin{array}{l}\text { Marketed MIZ } \\
\text { cream formulation }\end{array}$ \\
\hline C. albicans $(\mathrm{CP})$ & $43 \mathrm{~mm}$ & $47 \mathrm{~mm}$ \\
\hline
\end{tabular}

C. albicans: Candida albicans

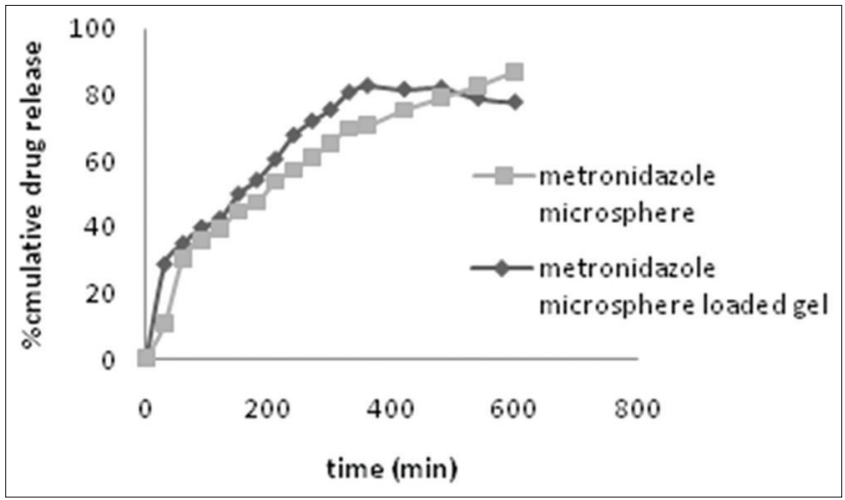

Fig. 7: In vitro release profile of metronidazole from microspheres and microspheres-loaded gel

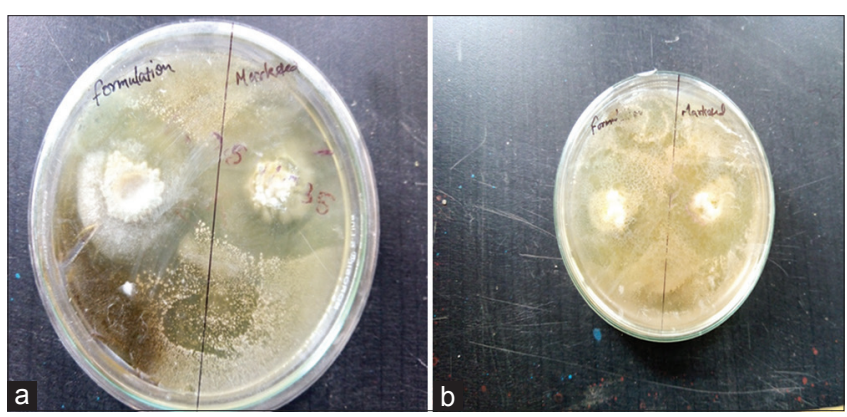

Fig. 8: ( $a$ and b) Comparison of antimicrobial activity of optimized vaginal gel with marketed metronidazole gel formulation

\section{CONCLUSION}

The formulated metronidazole-loaded PCL microspheres for sustained release were found to be potential and effective in terms of entrapment efficiency, particle size, partition coefficient, and in vitro drug release characteristics. The mucoadhesive gel formulation that consisted of drug-loaded PCL microspheres showed sustained release of $>10 \mathrm{hrs}$, indicating their suitability for the sustained delivery of the drug. The observed bioadhesive strength suggests enhanced retention of the applied gel in the vaginal sites that is helpful in sustained release as well as for effective drug absorption.

\section{REFERENCES}

1. Chien YW. Vaginal Drug Delivery and Delivery System, Novel Drug Delivery Systems. New York: Marcel Dekker Inc; 1992. p. 529-40.

2. Jones DS, Woolfson AD, Brown AF, O’Neill MJ. Mucoadhesive syringeable drug delivery systems for controlled application of metronidazole to periodontal pocket: In vitro release kinetics, syringeability, mechanical and mucoadhesive properties. J Control Release 1997;49(1):71-9.

3. Karthikeyan K, Durgadevi R, Saravanan K, Shivsankar K, Usha S, Saravanan M. Formulation of bioadhesive carbomer gel incorporating drug-loaded gelatin microspheres for periodontal therapy. Trop J Pharm Res 2012;11(3):335-43.

4. Tiwari G. Biodegradable microspheres for controlled delivery of metronidazole in the treatment of periodontal diseases: Formulation consideration. Int J Pharm Bio Sci 2010;1(2):1-13.

5. Sanap GS, Mohanta GS. Solid lipid nanoparticles - based hydrogel formulation for topical delivery of miconazole nitrate. Int J Pharm Bio Sci 2013;4(2):21-33

6. Kataria S, Middha A, Sandhu P, Bilandi A, Kapoor A. Microsphere: A review. Int J Res Pharm Chem 2011;1(4):1184-98.

7. Reddy KV, Patra PK, Divakar K, Reddy BV. Formulation and in vitro studies of carvedilol microspheres with its characterization. Int J Pharm Pharm Sci 2014;6(4):329-32.

8. Golomb G, Friedman M, Soskolne A, Stabholz A, Sela MN. Sustained release device containing metronidazole for periodontal use. J Dent Res 1984;63:1149-53.

9. Mukerjee A, Sinha VR, Pruthi V. Preparation and characterization of poly- $\varepsilon$-caprolactone particles for controlled insulin delivery. J Biomed Pharm Eng 2007;1(1):40-4.

10. Kim SY, Lee YM, Baik DJ, Kang JS. Toxic characteristics of methoxy poly(ethylene glycol)/poly(epsilon-caprolactone) nanospheres; in vitro and in vivo studies in the normal mice. Biomaterials 2003;24(1):55-63.

11. Patel PV, Daslaniya DJ, Patel UL, Shah R. Formulation and evaluation of bioadhesive gel incorporated amoxicillin trihydrate loaded microspheres for periodontal therapy. Int J Pharm Innov 2013;3(3):98-109.

12. Sharma YR. Elementary Organic Spectroscopy, Principles and Chemical Applications. Vol. 4. New Delhi: Rajendra Ravindra Printers Pvt., Ltd.; 2011. p. 64-113.

13. Parmar VJ, Lumbhani AN. Formulation and development of thermosreversible mucoadhesive intranasal in situ hydrogel by using a combination of polymers. Bull Pharm Res 2012;2(3):167-74.

14. Wu XG, Li G, Gao YL. Optimization of the preparation of nalmefeneloaded sustained-release microspheres using central composite design. 
Chem Pharm Bull 2006;54(7):977-81.

15. Reddy JR, Gnanaprakash K, Badarinath AV, Chetty CM. Formulation and evaluation of microparticles of metronidazole J Pharm Sci Res 2009;1(10):131-6.

16. Chowdary KP, Annapurna A. Influence of core and method of preparation on microencapsulation efficiency and drug release and permeability of ethyl cellulose microcapsules. East Pharm 1992;9:129-31.

17. Chadawar V, Shaji J. Microsponge delivery system. Curr Drug Deliv 2007:4(2):123-9.

18. Hani U, Bhat RS, Shivakumar HG. Formulation design and evaluation of metronidazole microspheres in a bioadhesive gel for local therapy of vaginal candidiasis. Lat Am J Pharm 2011:30(1):161-7.

19. Adimoolam S, Bhai TH, Vinod DM, Bharat LT, Battu BL. Formulation and evaluation of mucoadhesive microspheres of venlafaxin HCL. Int Res J Pharm 2011;2(4):194-9.

20. Galgatte UC, Chaudhari PD. Preformulation study of poloxamer 407 Gels: Effect of additives. Int J Pharm Pharm Sci 2014;1(1):130-3.

21. Chatterjee A, Bhowmik BB, Thakur YS. Formulation, in vitro and in vivo pharmacokinetics of anti-HIV vaginal bioadhesive Gel. J Young
Pharm 2011;3(2):83-9.

22. Deveda P, Jain A, Vyas N, Khambete H, Jain S. Gellified emulsion for sustain deliver of itrakonazole for topical fungal diseases. Int J Pharm Pharm Sci 2010;2(1):104-12.

23. Yellanki SK, Narella NK, Goranti S, Deb SK. Development of metronidazole intravaginal gel for the treatment of bacterial vaginosis, effect of mucoadhesive natural polymers on the release of metronidazole. Int J Pharm Res Dev 2010;2(3):1-6.

24. Karavana SY, Seda R, Zeynep S, Esra B. A new in-situ gel formulation of itraconazole for vaginal administration. Res J Pharmacol Pharm 2012;3(4):417-26

25. Kumar J, Muralidharan S, Parasuraman S. In vitro and in vivo evaluation of microspheres loaded topical gel delivery system of ketoconazole in male rats against Candida glabrata. J Pharm Sci Res 2014;6(11):376-81.

26. Mundhey DA, Morris PS, Lohiya GK, Avari JG. Formulation and evaluation of mucoadhesive vaginal gel containing novel combination of metronidazole and miconazole nitrate for the treatment of vaginitis. World J Pharm Sci 2015;4:910-8. 